\title{
Quantitative Research of Spatial Attribute from Urban Commercial Circles
}

\author{
ZHU Shanyao 1, a , LI Danyang ${ }^{2, b}$ \\ ${ }^{1}$ Xianning West Road, Xi'an, Shaanxi, 710049, P.R. China \\ ${ }^{2}$ Xianning West Road, Xi'an, Shaanxi, 710049, P.R. China \\ a82029964@qq.com, b18792883557@163.com
}

\begin{abstract}
Keywords: axial map, quantitative research, multivariable linear regression model, commercial potential.

Abstract. Based on the spatial syntactic axial model, combined with POI data, from the angle of urban road space structure, the paper chooses 10 representative commercial circles in Xi' an as the research object. Firstly, quantitatively calculates its commercial potential, then carries on spatial attribute analysis to the spatial attribute of its region. Finally, the mathematical regression model between commercial potential and spatial attributes is established. This model is used to evaluate the commercial potential of some sites in the main urban area and the surrounding areas to be developed, and to predict the possible future commercial areas and their scale and benefits.
\end{abstract}

\section{Research Objective and Content}

This study aims to explore the relation between the spatial law of city itself and the spatial attribute. It selects many commercial circles in Xi'an as the research object, combines the POI data to quantify the commercial capability, and establishes an accurate mathematical model, to help to forecast and evaluate the potential of commercial circle. Xi'an, as the millennium ancient city, through dynasties replacement, but it always retains the deep marrow of the urban context, and has been continuously strengthened in the city's thousands of years' development. Such a city, with extremely strong spatial regularity and thousands of years multiple constraints between rules intervention and self-organization, provides an interesting place for studying space of the city's commercial circle and the commercial potential.

In 1970, the space syntax proposed by Bill Hillier, Professor of Architecture in University of London, is the subject of studying urban space ontology, that is, to study the relevant category of urban space rules and attributes. The theory of Space syntax explains: "Individual space elements can't completely affect social and economic activities, but the complex relationship between spatial elements is the spatial factor of social economic activities and the factors that affect and determine social economic phenomena." [1]

In the age of big data, the commercial potential of commercial circles in our cities (including their commercial scale and popularity) can be quantified by POI data and visitors' flowrate. However, how to quantify the spatial attribute in the city? Space syntax provides us a good method. Based on the quantification of commercial potential and spatial attributes, the mathematical regression model is obtained by using the SPSS tool for linear regression analysis. It helps us to deepen our understanding of the relationship between the urban space rules and the spatial properties.

\section{Research Methods}

ü The Quantitative Analysis of the Commercial Circle. The scale and popularity of commercial circles, representing the benefit of the commercial circles, can quantify the operational ability and operational benefits of the commercial circles through a comprehensive consideration of the projections of POI information and population distribution in the city. 
ü The Drawing of Axial Map. Using the specialized software - depthmap of the spatial syntax theory, the precisely drawn map of Xi'an road network is translated into the axial map of urban scale, so as to calculate the inherent attributes of urban space.

ü Establishment of Mathematical Regression Model. It means, the mathematical relativity between the spatial attributes and the actual commercial circle is established, and the regression coefficients are determined to generate multivariate fitting formulas.

$\ddot{u}$ Result Verification and Application. Verify the accuracy of the research results, and draw the distribution of Xi'an commercial potential according to the calculation results, and analyze the transformation direction of future business context. As well as explain the significance of extending this method to other cities and other fields.

\section{Research Process}

Quantification of Commercial potential

"Xi' an commercial network development plan (2014-2020)" pointed out that from the perspective of building an international metropolis, we need vigorously develop Xi'an regional business center, and plan Xi'an regional commercial circle a total of 20. In this study, we extracted 10 representative commercial circles in Xi'an city. Using the "POI data" and "Population distribution thermodynamic diagram ", the commercial potential of a commercial circle is measured by the two factors of shop count and passenger flow.

The spatial distribution density of POI data (points of interests) can reflect the number of shops in different levels of urban central area. By calculating the score of POI in the commercial circle, it can accurately reflect the size of a commercial circle's shop.

With the example of the Xiaozhai, the score of this commercial circle can be obtained by weighted averaging of the POI data with the radius of $0.5 \mathrm{~km}, 1 \mathrm{~km}$ and $1.5 \mathrm{~km}$.

Table 1 shows the specific quantitative results of the 10 representative commercial circles, with the number of POI as the statistical objects from the AutoNavi map and Dianping.com, in which we set the largest number of reviews as 100 points and the lowest as 0 points:

Table 1

Sum and score of POI data of various commercial circles

\begin{tabular}{|c|c|c|c|c|c|}
\hline Commercial circle & $\begin{array}{c}\text { Total number of } \\
\text { AutoNavi }\end{array}$ & score & $\begin{array}{c}\text { Total number in } \\
\text { Dianping.com }\end{array}$ & score & $\begin{array}{c}\text { Average } \\
\text { score }\end{array}$ \\
\hline North Second ring & 1841.00 & 10.19 & 2575.00 & 4.18 & 7.19 \\
\hline Bell tower & 7303.00 & 100.00 & 15547.00 & 100.00 & 100.00 \\
\hline Qujiang & 3183.00 & 32.26 & 6276.00 & 31.52 & 31.89 \\
\hline Tumen & 1791.00 & 9.37 & 3650.00 & 12.12 & 10.75 \\
\hline High-tech zone & 5340.00 & 67.72 & 6502.00 & 33.19 & 50.46 \\
\hline Hongmiaopo & 1221.00 & 0.00 & 2260.00 & 1.85 & 0.93 \\
\hline Shapo & 2107.00 & 14.57 & 3032.00 & 7.56 & 11.06 \\
\hline Zhangjiabao & 1471.00 & 4.11 & 2009.00 & 0.00 & 2.06 \\
\hline Xiaozhai & 4037.00 & 46.30 & 9629.00 & 56.29 & 51.29 \\
\hline Hujiamiao & 1908.00 & 11.30 & 3462.00 & 10.73 & 11.01 \\
\hline
\end{tabular}

The thermodynamic map from Baidu and WeChat reflects the use of urban space, which shows the density of people in everywhere. Using the thermodynamic map function, the statistic calculation of the statistic visitors' flowrate in the large data can accurately reflect the scale of a commercial circle.

The study extracted the curve of visitors' flowrate score in 10 commercial circles on April 1, 2017 (Saturday), and selected the most representative of the visitors' flowrate which includes 12 o'clock, 16 o'clock, and 20 o'clock. 
When the lowest and highest visitors' flowrate from Baidu thermodynamic map are set as 0 and 100 , the scores and average scores of 10 commercial complexes at 12 o'clock, 16 o'clock and 20 o'clock are shown as Table 2. (That is, we set the peak of visitors' flowrate as 100.)

Table 2

Visitors' flowrate sum score and average score in different time periods of commercial circles

\begin{tabular}{|c|c|c|c|c|}
\hline Commercial circle & $12 \mathrm{o}^{\text {'clock }}$ & $16 \mathrm{o}^{\text {'clock }}$ & $20 \mathrm{o}^{\text {'clock }}$ & Average score \\
\hline North Second ring & 39.00 & 42.00 & 44.00 & 41.67 \\
\hline Bell tower & 53.00 & 62.00 & 58.00 & 57.67 \\
\hline Qujiang & 36.00 & 36.00 & 35.00 & 35.67 \\
\hline Tumen & 26.00 & 21.00 & 16.00 & 21.00 \\
\hline High-tech zone & 55.00 & 56.00 & 44.00 & 51.67 \\
\hline Hongmiaopo & 30.00 & 27.00 & 29.00 & 28.67 \\
\hline Shapo & 50.00 & 66.00 & 62.00 & 59.33 \\
\hline Zhangjiabao & 35.00 & 33.00 & 36.00 & 34.67 \\
\hline Xiaozhai & 68.00 & 82.00 & 75.00 & 75.00 \\
\hline Hujiamiao & 55.00 & 67.00 & 60.00 & 60.67 \\
\hline
\end{tabular}

First, we make the POI data in the region and visitors' flowrate statistics weighted, for example, North Second ring commercial circle's POI number is $7.91 / 100$, the visitors' flowrate is $41.67 / 100$, then these scores multiply with corresponding weights and calculate the score on a scale of $0-10$, and its final ability is $2.23 / 10$. Finally, we get a comprehensive score of commercial potential for commercial scale and visitors' flowrate (Table 3).

Table 3

Score of commercial potential for commercial scale and visitors' flowrate

\begin{tabular}{|c|c|c|c|}
\hline Commercial circle & $\begin{array}{c}\text { POI data } \\
\text { average score }\end{array}$ & $\begin{array}{c}\text { Visitors' flowrate } \\
\text { average score }\end{array}$ & $\begin{array}{c}\text { Score of commercial } \\
\text { potential }\end{array}$ \\
\hline North Second ring & 7.19 & 41.67 & 2.23 \\
\hline Bell tower & 100.00 & 57.67 & 8.40 \\
\hline Qujiang & 31.89 & 35.67 & 2.92 \\
\hline Tumen & 10.75 & 21.00 & 0.50 \\
\hline High-tech zone & 50.46 & 51.67 & 5.34 \\
\hline Hongmiaopo & 0.93 & 28.67 & 0.71 \\
\hline Shapo & 11.06 & 59.33 & 4.06 \\
\hline Zhangjiabao & 2.06 & 34.67 & 7.32 \\
\hline Xiaozhai & 51.29 & 75.00 & 4.18 \\
\hline Hujiamiao & 11.01 & 60.67 & \\
\hline
\end{tabular}

Quantification of Spatial Attributes--a Study of Spatial Syntactic Axial Model

The paper chooses four correlative parameter values to characterize the spatial structure of road network, which are control, mean depth, integration $(\mathrm{HH})$ and local integration respectively in Table 4.(in Fig.1, red indicates a higher value, and blue indicates a lower value). 


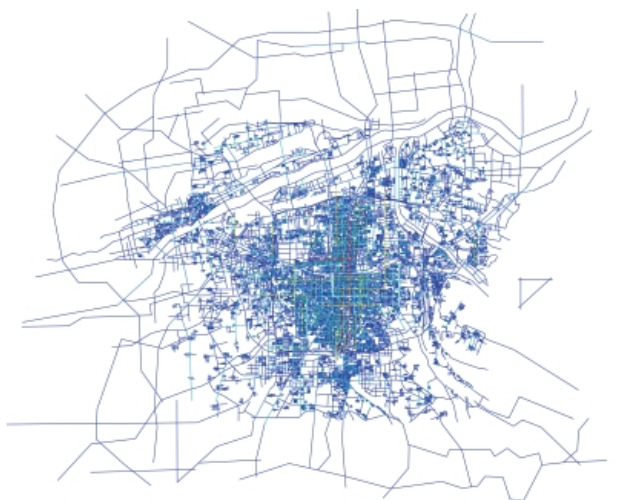

b) axial map of control

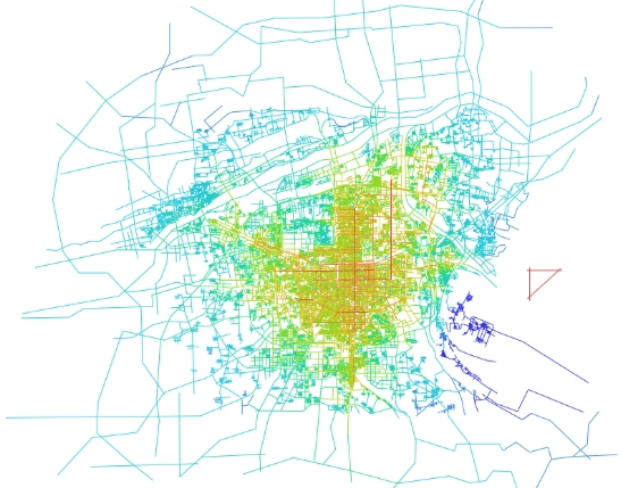

c) axial map of local intergration

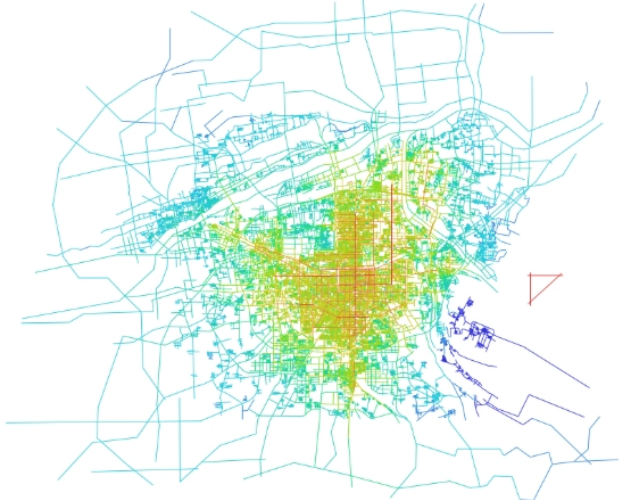

a) axial map of intergration $(\mathrm{HH})$

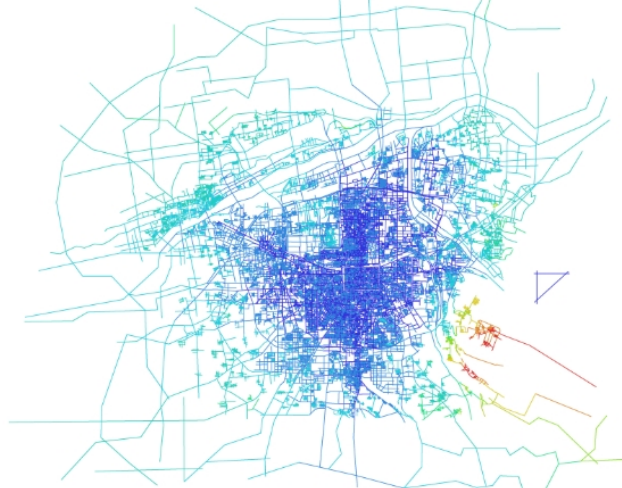

d) axial map of mean depth

Fig.1. Four related parameter values in spatial syntax (exported from Depthmap)

Table 4

Four spatial attributes of ten representing commercial circles extracted from Depthmap

\begin{tabular}{|c|c|c|c|c|}
\hline Commercial circle & Control & Integration (HH) & Integration R3 & Mean depth \\
\hline North Second ring & 18.2935 & 1.83401 & 5.07833 & 7.66991 \\
\hline Bell tower & 15.3343 & 1.88816 & 5.02448 & 7.47861 \\
\hline Qujiang & 8.00911 & 1.74525 & 4.56593 & 8.00911 \\
\hline Tumen & 5.52091 & 1.74879 & 4.22933 & 7.99494 \\
\hline High-tech zone & 8.15213 & 1.61261 & 4.3625 & 8.58566 \\
\hline Hongmiaopo & 3.85305 & 1.69538 & 4.16764 & 8.21531 \\
\hline Shapo & 2.86118 & 1.57296 & 3.67553 & 8.77686 \\
\hline Zhangjiabao & 18.2935 & 1.83401 & 5.07833 & 7.66991 \\
\hline Xiaozhai & 15.3343 & 1.88816 & 5.02448 & 7.47861 \\
\hline Hujiamiao & 14.2071 & 1.8244 & 4.7051 & 7.70504 \\
\hline
\end{tabular}

The Bell Tower and the Xiaozhai area as two big commercial core area in Xi' an, its influence undoubtedly is the biggest. In Table 3, this fact has been proving that integration (HH) of both is at the highest (1.88816), while the mean depth is at the lowest (7.47861).

\section{The Establishment of Regression Model}

Multivariate statistical analysis is a branch of mathematical statistics. It studies how to effectively collate and analyze data affected randomly and make inferences or predictions about the problems. By using SPSS (statistical package for the social science), this study establishes the function of $\mathrm{Y}$ as commercial complex scale and $\mathrm{X}$ as space attribute. That is to say, by using this function relationship, you can calculate the theoretical commercial potential of a place by determining the value of the space attribute. Exactly, the axial map in depthmap covers the exact value of every spatial attribute in the city. 
In this model, the control, mean depth, integration $(\mathrm{HH})$ and local integration of the axial map of Metro Line 3 are selected as the explanatory variables, and the commercial potential score is set as the explained variable.

Imported data in Table 5-1 into SPSS, then get the results as shown in Table 5-2 and Table 5-3.

Table 5-1

Variables of multivariate linear regression model

\begin{tabular}{|c|c|c|c|c|c|}
\hline Commercial circle & $\begin{array}{c}Y \\
\text { Score of commercial } \\
\text { potential }\end{array}$ & $\begin{array}{c}X_{1} \\
\text { control }\end{array}$ & $\begin{array}{c}X_{2} \\
\text { Integration (HH) }\end{array}$ & $\begin{array}{c}X_{3} \\
\text { local integration }\end{array}$ & $\begin{array}{c}X_{4} \\
\text { mean depth }\end{array}$ \\
\hline North Second ring & 2.23 & 18.3766 & 1.98896 & 5.09122 & 7.15037 \\
\hline Bell tower & 8.40 & 15.366 & 2.03708 & 5.03892 & 7.00509 \\
\hline Qujiang & 2.92 & 9.01828 & 1.84516 & 4.56871 & 7.62969 \\
\hline Tumen & 0.50 & 5.52091 & 1.81266 & 4.23022 & 7.74855 \\
\hline High-tech zone & 5.34 & 8.22821 & 1.86665 & 4.41435 & 7.55335 \\
\hline Hongmiaopo & 0.71 & 3.8493 & 1.81584 & 4.17289 & 4.17289 \\
\hline Shapo & 4.06 & 2.9381 & 1.81489 & 3.81337 & 7.74027 \\
\hline Zhangjiabao & 1.32 & 18.3766 & 1.98896 & 5.09122 & 7.15037 \\
\hline Xiaozhai & 7.54 & 15.366 & 2.03708 & 5.03892 & 7.00509 \\
\hline Hujiamiao & 4.18 & 14.2819 & 1.94571 & 4.73276 & 7.28707 \\
\hline
\end{tabular}

Table 5-2

Model data collection

\begin{tabular}{|c|c|c|c|c|c|}
\hline Model & $\mathrm{R}$ & $\mathrm{R}^{2}$ & $\begin{array}{c}\text { Adjustment value } \\
\text { of } \mathrm{R}^{2}\end{array}$ & Standard estimate error & Durbin-Watson \\
\hline 1 & 0.910 & 0.827 & 0.689 & 1.52645 & 2.821 \\
\hline
\end{tabular}

As can be seen from Table $5-2, \mathrm{R}^{2}$ is 0.827 , so the regression model is established and statistically significant.

Table 5-3

Coefficient

\begin{tabular}{cccc}
\hline \multirow{2}{*}{ model } & \multicolumn{2}{c}{ Unstandardized Coefficients } \\
\cline { 3 - 4 } & & $\mathrm{B}$ & Standard Error \\
\hline & (Constant) & -121.960 & 29.261 \\
& Control & -0.987 & 0.407 \\
\multirow{2}{*}{1} & Global Integration & 61.441 & 14.656 \\
& Local Integration & 2.578 & 5.203 \\
& Mean Depth & 1.010 & 0.533 \\
\hline
\end{tabular}

The final definite regression equation as follows:

$$
Y=-121.960-0.987 X_{1}+61.441 X_{2}+2.578 X_{3}+1.010 X_{4}
$$

Based on the calculation of the equation, the potential of Xi'an's commercial regional capacity distribution is finally obtained (Fig.2). 


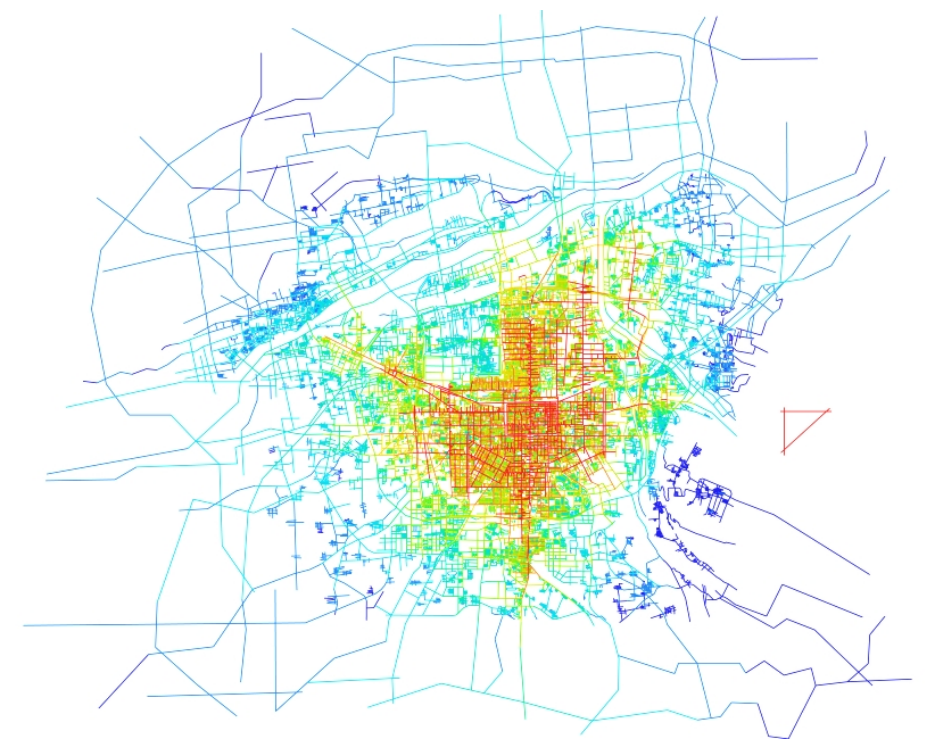

Fig.2. the calculation score axial map of Xi' an commercial (scale) potential (exported from Depthmap)

\section{Conclusion}

This study takes the commercial potential of Xi'an commercial circles as the research object, establishes the corresponding mathematical regression model based on the large data information, and generates a set of methods to get the data connection by studying the relation between the spatial attribute and the commercial phenomenon. More importantly, this method makes it more accurate to predict the economic activities that will occur within the space of the computer in space design. It can be applied in the following situations.

$\ddot{u}$ A quantitative assessment of the commercial potential of different established commercial circles.

ü The accurate commercial potential forecast of commercial circles to be developed in urban area.

$\ddot{u}$ The forecast of the future development trend of $\mathrm{Xi}$ ' an commercial area to establish traceable research basis for business investment.

By extension, this method can also apply to other types of construction facilities in various regions' research and discussion (such as the distribution square, second-hand trading market, etc). The mathematical regression model can be established in the same way, and the spatial quantitative analysis, prediction and planning of this type of building facilities are carried out. By changing the $\mathrm{Y}$ (space phenomenon) and reconnecting with the $\mathrm{X}$ (space attribute) to establish the corresponding relationship, the equation of $\mathrm{Y}$ (space phenomenon) about $\mathrm{X}$ (space attribute) is obtained.

\section{Acknowledgements}

This work was financially supported by The National Natural Science Fund, Program of Quantifying the impact what recreational sites have on urban space in Xi'an (51508457).

\section{References}

[1] Bill Hillier, Jin Duan. Space Synax in China. Southeast University. 2015: 18-36. (In Chinese)

[2] Dawson P C. Space syntax analysis of Central Inuit snow houses. Journal of Anthropological Archaeology, 2002, 21(4):464-480.

[3] Croxford B, Penn A, Hillier B. Spatial distribution of urban pollution: civilizing urban traffic. Science of the Total Environment, 1996, 189(96):3-9. 
[4] Hong - kyu kirn, Dong Wook Sohn. An analysis of the relationship between land use density of office configuration. Cities, 2002, (6)

[5] Dongfeng Zhu. A Case Study of City Suzhou on Urban Inner Centralities Basing on Space syntax Methods. Modern Urban Research, 2006, 21(12):60-67. (In Chinese)

[6] Qiang Sheng. Urban Labyrinth: Space, Process and Complex System. World Architecture, 2005(11):92-95. (In Chinese)

[7] Hillier B, Penn A, Hanson J, et al. Natural movement: or, configuration and attraction in urban pedestrian movement. Environment and Planning B: Planning and Design, 1993, 20(1):29-66.

[8] Peponis J, Ross C, Rashid M. The structure of urban space, movement and co-presence: The case of Atlanta. Geoforum, 1997, 28(s 3-4):341-358.

[9] Raford N. Pedestrian Movement and Neighborhood Morphology in Fractured Spatial System: The Case of Boston, Massachusetts. World Architecture, 2005.

[10] Mingxing Chen, Fei Sheng, Liangsong Zha, Baoshi Jin. A Research on Urban Traffic Network Based on Space Syntax:A Case Study on Wuhu City. Geography and Geo-Information Science, 2005, 21(2):39-42. (In Chinese)

[11] Ruilan Duan, Xinqi Zheng. The relation of the city road structure and the land price based on the space syntax. Science of Surveying and Mapping, 2004, 29(5):76-79. (In Chinese)

[12] Ling Zhang. Research on POI Classification Standard. Bulletin of Surveying and Mapping, 2012,10:82-84. (In Chinese)

[13] Bo Guo, Yuetong Xu, Wei-jun Sun. Accessibility of Regional POI Based on the Network Analysis of Arc GIS. Journal of Ludong University (Natural Science Edition), 2015,01:68-71. (In Chinese)

[14] Weifeng Zhao, Qingquan Li, Bijun Li. Extracting hierarchical landmarks from urban POI data. Journal of Remote Sensing, 2011,05:973-988. (In Chinese)

[15] Zhiqiang Wu, Zhongnan Ye. Research on Urban Spatial Structure Based on BAIDU Heat Map: a Case Study on The Central City of Shanghai. City Planning Review, 2016,(04):33-40. (In Chinese)

[16] Yongsheng Chen, Lixin Song. Multiple Linear Regression Modeling and SPSS Software Solving. Journal of Tonghua Normal University, 2007,(12):8-9+12. (In Chinese)

[17] Xi’an Commercial Network Development Plan (2014-2020). 2004-12. (In Chinese) 